\title{
Fontes de infecção e perfil de suscetibilidade aos antimicrobianos de Salmonella sp. isoladas no fluxo de produção de frangos de corte
}

\author{
Sources of infection and antimicrobial susceptibility profile of \\ Salmonella sp. isolated in broiler production flow
}

\section{Dunya Mara Cardoso Moraes ${ }^{1}$, Maria Auxiliadora Andrade ${ }^{1 *}$, Cíntia Silva Minafra-Rezende', Ana Caroline de Souza Barnabé1, Valéria de Sá Jayme'1, Iolanda Aparecida Nunes', Dayana de Andrade Batista'}

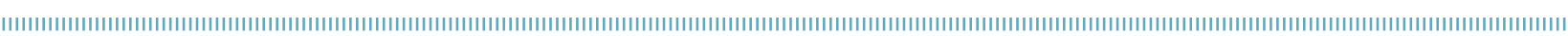

\begin{abstract}
RESUMO: Este trabalho foi desenvolvido com objetivo de pesquisar Salmonella em amostras de fígado, coração, saco da gema e mecônio de pintos de corte de um dia; inglúvios e cecos obtidos em abatedouros e em suabes de arrasto; larvas ou adultos de Alphitobius diaperinus. Complementarmente, determinou-se o perfil de suscetibilidade aos antimicrobianos: amoxicilina $(10 \mathrm{mcg})$, ampicilina $(10 \mathrm{mcg})$, ciprofloxacina (5 mcg), enrofloxacina (5 mcg), florfenicol (30 mcg), neomicina $(30 \mathrm{mcg})$, sulfonamida $(300 \mathrm{mcg})$, tetraciclina $(30 \mathrm{mcg})$ e trimetoprim-sulfametoxazol ( $25 \mathrm{mcg}$ ) dos serovares tipificados isolados. As amostras foram submetidas às análises microbiológicas pelos métodos bacteriológicos convencionais. Salmonella sp. foi isolada em 6,2\% (4/64) do fígado, 4,7\% (3/64) do coração, 3,1\% (2/64) dos sacos da gema e 4,7\% (3/64) do mecônio, num total de 4,7\% (12/256) (pinto de um dia); em 10,2\% (13/128) das amostras ambientais, sendo 9,4\% (9/96) de suabes de arrasto 12,5\%, (4/32) de larvas e adultos Alphitobius diaperinus e em 4,4\% (28/640) das amostras em abatedouros, sendo 6,5\% (21/320) dos inglúvios e 2,2\% (7/320) dos conteúdos cecais de abatedouro. Salmonella enterica ser. Enteritidis foi identificada em suabes de arrasto e em amostras de Alphitobius diaperinus, enquanto Salmonella enterica ser. Typhimurium foi encontrada nos inglúvios e cecos. Salmonella enterica ser. Enteritidis apresentaram 75\% (6/8) de resistência às sulfonamidas e Salmonella enterica ser. Typhimurium $100 \%(3 / 3)$. A amoxicilina foi outro antimicrobiano com elevada frequência de resistência. Adicionalmente, 20,7\% (11/53) dos serovares apresentaram resistência simultânea a pelo menos dois princípios ativos. Conclui-se que Salmonella encontra-se amplamente distribuída no fluxo de produção de frangos de corte, e a via vertical continua sendo uma fonte de introduçáo de Salmonella sp. à cadeia de produção; cama e insetos podem perpetuar e veicular Salmonella de interesse zoonótico no ambiente avícola; a existência de cepas resistentes aos antimicrobianos, bem como a resistência múltipla, constituem ameaça à saúde pública.
\end{abstract}

PALAVRAS-CHAVE: abatedouro; Alphitobius diaperinus; ambiente; antibióticos; resistência.

\begin{abstract}
This work aimed at searching for Salmonella in liver, heart, yolk sac and meconium samples of one-day-old chicks, crops and cecum samples from slaughterhouses and drag swabs and Alphitobius diaperinus larvae or adults. It also aimed at determining the susceptibility profile to amoxicillin (10 mcg), ampicillin (10 mcg), ciprofloxacin (5 mcg), enrofloxacin (5 mcg), florfenicol (30 mcg), neomycin (30 mcg), sulfonamide $(300 \mathrm{mcg})$, tetracycline $(30 \mathrm{mcg})$ and trimethoprim-sulfamethoxazole $(25 \mathrm{mcg}$ ) of typed serovars isolated. The samples were submitted to microbiological analyses by the conventional method. Salmonella sp. was isolated in 4.7\% (12/256) of samples of one-day old chicks, in $6.2 \%$ (4/64) of the liver, $4.7 \%$ $(3 / 64)$ of the hearts, $3.1 \%(2 / 64)$ of the yolk sacs, $4.7 \%(3 / 64)$ of meconium, and in $10.2 \%$ (13/128) of the environment samples, being 9.4\% (9/96) from drag swabs, $12.5 \%$ (4/32) from larvae and adult Alphitobius diaperinus and 4.4\% (28/640) of the slaughterhouses samples, being 6.5\% (21/320) of crops and $2.2 \%(7 / 320)$ of cecum samples. Salmonella enterica ser. Enteritidis was identified only in drag swabs and Alphitobius diaperinus. Salmonella enterica ser. Typhimurium was observed in the crops and cecum, which have shown high frequency of resistance to sulfonamides, $75 \%(6 / 8)$ and $100 \%(3 / 30)$, respectively. Additionally, 20.7\% (11/53) of the serovars have shown multiresistance to at least two of the tested drugs. In conclusion, Salmonella can be widely spread in broiler production flow, and the vertical pathway is still a major source of Salmonella insertion in the poultry production chain. The litter and bugs can perpetuate and disseminate Salmonella sp. as well as both the existence of strains resistant to antimicrobial and the occurrence of multiresistance are a threat to public health.
\end{abstract}

KEYWORDS: slaughterhouse; Alphitobius diaperinus: environment; antibiotics; resistance. 


\section{INTRODUÇÃO}

A salmonela, um importante patógeno zoonótico de distribuiçấo mundial, é apontada como agente causador de toxinfecçấo alimentar em países em desenvolvimento e nos desenvolvidos (SCHLUndt et al., 2004). Conforme BACK (2011), a bactéria possui características epidemiológicas complexas que favorecem sua distribuiçáo no meio ambiente, o que contribui para seu elevado impacto em saúde pública. De fato, estes micro-organismos podem sobreviver por longos períodos em reservatórios diversos, como ambiente, solo, água e cama de aviário (Newell et al., 2010). Outra forma de manutenção do patógeno nos sistemas de produção é a presença do portador inaparente, que elimina o patógeno via ovo, sendo que a incubação de ovos férteis pode resultar em pintos infectados (ANDRADE et al., 2008).

Além disso, artrópodes como Alphitobius diaperinus (Coleoptera: Tenebrionidae), são potenciais reservatórios de bactérias, podendo infectar lotes sucessivos e ainda contaminar o solo e a água, independentemente da fase de alojamento das aves (Rodrigues, 2005).

Outro aspecto que merece ser apontado é a possibilidade de ocorrer contaminação cruzada durante as operaçôes de abate e processamento das carcaças. Além dessas possibilidades de contaminaçáo dos alimentos no fluxo de produção, é constante a preocupação das autoridades sanitárias à veiculação de fenótipos bacterianos resistentes aos antimicrobianos via produtos avícolas (FAO, 2007; YANG et al., 2010).

A utilização incorreta dos antimicrobianos em medicina humana e veterinária pode dificultar a eficácia do tratamento e a recuperaçáo de indivíduos doentes. Este aspecto é agravado por evidências já apontadas por Cox; Pavic (2010), de que alguns antimicrobianos podem facilitar a colonização, aumentar a excreção fecal e prolongar a disseminação e o estado de portador de Salmonella.

A resistência das bactérias aos antimicrobianos é um motivo de preocupação tanto para a saúde publica como para a saúde animal (OIE, 2012), e varia em determinada área geográfica e espaço de tempo. Em funçáo disso, para produzir alimento seguro, um conjunto de práticas e procedimentos deve ser adotado desde o ambiente criatório das aves até a comercialização, incluindo as fases de pré-abate e de abate das aves (Rodrigues, 2005; Silva, 2005).

Considerando os preceitos da segurança alimentar, assim como os riscos associados aos produtos contaminados por agentes zoonóticos e atribuídos aos fenótipos resistentes aos antimicrobianos, objetivou-se com este trabalho a pesquisa de Salmonella em amostras de pintos de um dia, de ambientes de criaçáo e abatedouros localizados no estado de Goiás, bem como determinar o perfil de suscetibilidade aos antimicrobianos de serovares identificados.

\section{MATERIAL E MÉTODOS}

A pesquisa foi realizada no Laboratório de Bacteriologia do Departamento de Medicina Veterinária da Escola de Veterinária e Zootecnia, na Universidade Federal de Goiás,

As amostras foram constituídas por pintos de um dia coletados nos próprios caminhôes de transporte, em fase anterior ao alojamento, por suabes de arrasto, larvas ou cascudinhos adultos obtidos em galpóes, e vísceras (inglúvios e cecos) obtidas em abatedouros. Dos isolados, procedeu-se a pesquisa de suscetibilidade a antimicrobianos.

As amostras, de 32 lotes, foram coletadas em aviários convencionais, localizados em 16 municípios do estado de Goiás no período de um ano.

Pintos de um dia, dez por lote, foram coletados diretamente dos caminhóes, conduzidos ao laboratório e submetidos à necropsia, onde se fez a coleta de coração, fígado, saco da gema e conteúdo intestinal (mecônio).

Em galpóes de criação foram realizados suabes de arrasto, ao longo das linhas de bebedouros e comedouros, com o auxílio de pró-pés esterilizados, na última semana do alojamento, num total de 96 amostras, sendo três amostras por galpão.

As amostras de larvas ou "cascudinhos" adultos foram coletadas com o auxílio de armadilhas que consistiram em tubos de plástico de policloreto de polivinila (PVC), que foram enterrados na cama e distribuídos aleatoriamente em dez pontos nos galpóes. Os insetos entravam juntamente com a cama dentro dos tubos PVC e, posteriormente, com uma pinça, eram retirados e colocados em placas de Petri esterilizadas. Foram coletadas 32 amostras desses insetos.

Durante o abate, foram coletadas dez amostras por lote, as quais foram constituídas de pool de cinco órgãos ou conteúdo, num total de 320 amostras de inglúvio, e a mesma quantidade de cecos, que foram acondicionados em bolsas, identificados e transportados ao laboratório.

Todas as amostras, após a identificação, foram acondicionadas em bolsas apropriadas para amostragem, transferidas para caixas isotérmicas contendo gelo em gel e imediatamente transportadas ao laboratório.

Os pintos foram submetidos à necropsia, e órgáos como coração, fígado, saco da gema e mecônio foram coletados, colocados em placa de Petri, separadamente, até completar cinco órgãos ou conteúdo da mesma categoria. Portanto, cada cinco pintos constituíram quatro amostras em forma de pool de coração, fígado, saco da gema e mecônio, sendo oito amostras por galpão. Cada amostra foi macerada e transferida na proporção de 1:10 para os caldos selenito cistina (CS) e Rappaport Vassiliadis (RV).

No laboratório, em condiçôes assépticas, as amostras ambientais e de insetos foram diluídas na proporção de 1:10, em peso ou volume, de acordo com a categoria da amostra, em soluçáo salina esterilizada a $0,85 \%$, contendo $0,1 \%$ de peptona. 
O conteúdo dos inglúvios foi coletado assepticamente com o auxílio de um suabe, e aproximadamente $1 \mathrm{~g}$ de conteúdo dos cecos e cinco suabes de inglúvio, pool de cinco, foram dispensados em tubos contendo $9 \mathrm{~mL}$ de caldos CS e $10 \mathrm{~mL}$ de caldos $\mathrm{RV}$, respectivamente. As amostras foram analisadas conforme as recomendaçóes do Georgia Poultry Laboratory (1997) e Brasil (2003).

Após isolamento e diante de reações bioquímicas compatíveis com Salmonella, os isolados foram submetidos ao teste sorológico com soro polivalente anti-O. Aqueles que apresentaram resultados positivos foram remetidos à Fundação Instituto Oswaldo Cruz (FIOCRUZ-RJ) em ágar nutriente, para tipificação sorológica.

O perfil de suscetibilidade aos antimicrobianos foi determinado pelo método de Difusão em Disco, de acordo com o National Committee For Clinical Laboratory Standards (2002). Foram testados amoxacilina (amo) $-10 \mathrm{mcg}$, ampicilina (amp) - $10 \mathrm{mcg}$, ciprofloxacina (cip) $-5 \mathrm{mcg}$, enrofloxacina (enr) $-5 \mathrm{mcg}$, florfenicol (fff) $-30 \mathrm{mcg}$, neomicina (neo) $-30 \mathrm{mcg}$, sulfonamida (suf) $-300 \mathrm{mcg}$, tetraciclina (tet) $-30 \mathrm{mcg}$ e trimetoprim-sulfametoxazol (sut) $-25 \mathrm{mcg}$.

\section{RESULTADOS E DISCUSSÃO}

Salmonella sp. foi isolada em todas amostras estudadas (Tabela 1). O isolamento de Salmonella sp. em amostras de pintos de um dia, antes do alojamento, indica a ocorrência de transmissão vertical da bactéria, pois, das 256 amostras analisadas, 12 $(4,7 \%)$ foram positivas. Salmonella sp. isoladas originaram-se, provavelmente, das matrizes, ou os ovos se infectaram no incubatório. Os incubatórios comerciais săo ambientes de potencial contaminaçấo e disseminação de enteropatógenos. Além disso, segundo Mitchell et al. (2002), as partículas de pó geradas a partir de ovos contaminados dentro de um nascedouro podem espalhar enteropatógenos para outras áreas da incubadora, dependendo do fluxo do ar, e infectar os pintos.

Em trabalho realizado com o mesmo propósito, RochA et al. (2003) detectaram Salmonella sp. em 55,5\% dos mecônios de forros de caixa de transporte. Destaca-se que no presente trabalho as principais salmonelas de interesse zoonótico não foram identificadas nas amostras provenientes de pintos de um dia (Tabela 2).

Em relaçáo às amostras ambientais, Salmonella sp. foi detectada tanto em suabes de arrasto como nos "cascudinhos" (Tabela 1) em 10,2\% (13/128). Verifica-se ainda que 12,5\% (4/32) das amostras de Alphitobius diaperinus, "cascudinhos", foram positivas para Salmonella sp.. Este coleóptero se alimenta de aves moribundas, carcaças, fezes e raçóes, e a ave pode se infectar consumindo a cama que contém as larvas e os adultos contaminados, os quais podem permanecer semanas no ambiente avícola e ainda podem contaminar lotes alojados posteriormente (HAZELEGER et al., 2008; LefFer et al., 2010; Roche et al., 2009). Portanto, a presença deste inseto se constitui em um risco potencial de infecção por Salmonella para as aves e produtos, assim como para a segurança dos alimentos, principalmente porque Salmonella enterica serovar Enteritidis é o agente mais isolado de suabes de arrasto e o único isolado de "cascudinhos" (Tabela 2).

Os resultados obtidos neste trabalho corroboram os resultados de Hald (1998), que encontrou o micro-organismo em $45 \%$ das amostras de "cascudinhos" durante o intervalo de saída e entrada de lotes. Não obstante, SEgABInAZI et al. (2005) registraram 0,37\% de amostras positivas para Salmonella nas 54 examinadas, enquanto Chernaki-Leffer et al. (2002) não encontraram Salmonella sp. em amostras de "cascudinhos" coletados em aviários de frangos de corte.

A presença de Salmonella em 9,4\% (9/96) dos suabes de arrasto difere-se dos resultados descritos por Bonsor et al. (2006) que, ao pesquisarem 101 amostras de suabes de arrasto, encontraram 15,8\% das amostras positivas, e por BONI (2007), que, ao analisar 134 amostras de suabes de arrasto, encontrou $3,7 \%$ das amostras positivas.

Nas amostras de abatedouros, 320 de inglúvios e igual número de cecos, Salmonella sp. foi isolada em 4,4\% (28/640), sendo $6,5 \%(21 / 320)$ e 2,2\% (7/320) dos inglúvios e cecos,

Tabela 1. Frequência de Salmonella sp. isoladas no fluxo de produção de frangos de corte e no abatedouro de 32 lotes de frango de corte.

\begin{tabular}{|c|c|c|c|}
\hline & $\begin{array}{c}\text { Número de } \\
\text { amostras } \\
\text { coletadas }\end{array}$ & & $\begin{array}{l}\text { de } \\
\text { as } \\
\text { las }\end{array}$ \\
\hline & \multicolumn{3}{|c|}{ Pintos de um dia } \\
\hline Fígado* & 64 & 4 & 6,2 \\
\hline Coração* & 64 & 3 & 4,7 \\
\hline Saco da gema* & 64 & 2 & 3,1 \\
\hline Mecônio* & 64 & 3 & 4,7 \\
\hline \multirow[t]{2}{*}{ Total } & 256 & 12 & 4,7 \\
\hline & \multicolumn{3}{|c|}{ Amostras ambientais } \\
\hline Suabes de arrasto & 96 & 9 & 9,4 \\
\hline Cascudinhos & 32 & 4 & 12,5 \\
\hline \multirow[t]{2}{*}{ Total } & 128 & 13 & 10,2 \\
\hline & \multicolumn{3}{|c|}{ Amostras de abatedouros } \\
\hline Inglúvios * & 320 & 21 & 6,5 \\
\hline $\operatorname{Cecos}^{*}$ & 320 & 7 & 2,2 \\
\hline Total & 640 & 28 & 4,4 \\
\hline
\end{tabular}

* pool de cinco órgãos ou conteúdos de ceco e de inglúvios constituíram uma amostra 
Tabela 2. Frequência dos serovares de Salmonella no fluxo de produção de frangos de corte e no abatedouro.

\begin{tabular}{|c|c|c|c|c|c|c|c|}
\hline \multirow{3}{*}{$\begin{array}{l}\text { Salmonella } \\
\text { enterica serovar }\end{array}$} & \multicolumn{5}{|c|}{ Transmissão } & \multirow{2}{*}{\multicolumn{2}{|c|}{ Cepas }} \\
\hline & \multirow{2}{*}{$\begin{array}{c}\text { Vertical } \\
\text { Pintos de } \\
\text { um dia }\end{array}$} & \multicolumn{4}{|c|}{ Horizontal } & & \\
\hline & & $\begin{array}{l}\text { Suabes } \\
\text { de arrasto }\end{array}$ & Cascudinhos & Inglúvios & Cecos & $\mathbf{n}$ & $\%$ \\
\hline Schwarzengrund & 3 & - & - & 11 & 1 & 15 & 28,3 \\
\hline Enteritidis & - & 4 & 4 & - & - & 8 & 15,1 \\
\hline Cerro & 2 & - & - & 5 & - & 7 & 13,2 \\
\hline Rissen & 1 & - & - & 2 & 1 & 4 & 7,5 \\
\hline Johannesburg & 1 & - & - & - & 3 & 4 & 7,5 \\
\hline Typhimurium & - & - & - & 3 & - & 3 & 5,7 \\
\hline Havana & 1 & 2 & - & - & - & 3 & 5,7 \\
\hline Mbandaka & 1 & 1 & - & - & 1 & 3 & 5,7 \\
\hline Alachua & 2 & - & - & - & - & 2 & 3,8 \\
\hline Hadar & 1 & 1 & - & - & - & 2 & 3,8 \\
\hline Muenster & - & 1 & - & - & - & 1 & 1,9 \\
\hline Worthington & - & - & - & - & 1 & 1 & 1,9 \\
\hline Total & 12 & 9 & 4 & 21 & 7 & 53 & 100 \\
\hline$\%$ & 22,6 & 17,0 & 7,5 & 39,6 & 13,2 & - & - \\
\hline
\end{tabular}

respectivamente. Os serovares identificados nos dois órgãos foram os mesmos, embora a maior frequência de isolamento tenha sido obtida no inglúvio.

Essa maior frequência de isolamentos no inglúvio se deve provavelmente ao jejum no pré-abate, que alterou a população de lactobacilos. Tal condição está consonante com as proposiçóes de Hinton et al., (2000), que apontaram que o aumento do $\mathrm{pH}$, devido a modificaçóes da população do lúmen do inglúvio, diminui a capacidade de inibir o desenvolvimento de enterobacterias, inclusive de Salmonella. Por outro lado, Silva (2006) náo isolou Salmonella sp. nas amostras de inglúvios e cecos pesquisadas, enquanto VIEIRA et al. (2007) obtiveram frequência de 0,58\% (2/347) em cecos. Independentemente da frequência observada do patógeno no inglúvio e no ceco, Salmonella sp. pode gerar contaminação cruzada durante o processamento, ou seja, ser veiculada desses segmentos do trato gastrintestinal para a carcaça, conferindo risco à saúde pública.

Foram tipificadas 53 cepas de Salmonella sp. nas diferentes categorias de amostras, sendo 22,6\% (12/53) provenientes de pintos de um dia, 17,0\% (9/53), de suabes de arrasto, 7,5\% (4/53), de "cascudinhos", 39,6\% (21/53), de inglúvios e 13,2\% (7/53), de cecos. Observa-se ainda, na mesma Tabela, que Salmonella enterica serovar Schwarzengrund foi a cepa mais prevalente, em 28,3\% (15/53) das amostras de pinto de um dia, em inglúvios e cecos, seguida por Salmonella enterica serovar Enteritidis, em 15,2\% (8/13) das amostras ambientais.

Ao analisar os serovares identificados nas diferentes categorias de amostras (Tabela 2), verificam-se que os isolados das amostras de pintos de um dia foram praticamente os mesmos tipificados nas amostras de inglúvio e ceco, com exceção de Salmonella enterica serovar Typhimurium. A identificação dos mesmos serovares durante a produçáo de frangos e ao abate sugere que as bactérias se mantiveram no intestino de aves, durante toda a vida, sem determinar nenhum processo patológico, indicando o estado de portador. De acordo com ANDRADE et al., (2008) a ave portadora inaparente é um dos componentes da cadeia epidemiológica de Salmonella mais preocupantes para a saúde pública.

Os serovares identificados neste estudo podem ser categorizados como não-invasivos, componentes da microbiota intestinal, e ainda assim são riscos em potencial para a saúde pública, considerando os preceitos da segurança alimentar. Por outro lado, Salmonella enterica serovar Typhimurium, identificada apenas no inglúvio, tem sido caracterizada como serovar de alta patogenicidade, pela capacidade de causar toxinfecção no homem.

O perfil de resistência dos serovares de Salmonella frente a diferentes antimicrobianos é demonstrado na Tabela 3. Os maiores índices de resistência foram observados frente às sulfonamidas, 73,6\% (39/53), seguidos pela amoxacilina, $18,9 \%(10 / 53)$, trimetoprim-sulfametoxasole e tetraciclina, $13,2 \%(7 / 53)$, e $5,7 \%(3 / 53)$ para ampicilina e enrofloxacina. A maior frequência de resistência foi observada para os grupos de antimicrobianos mais comumente utilizados em criaçôes avícolas.

Observa-se, ainda, que os sorovares de maior relevância zoonótica, Salmonella enterica serovar Enteritidis e Salmonella 
Tabela 3. Número e percentual de resistência a nove antimicrobianos de 53 serovares de Salmonella.

\begin{tabular}{|c|c|c|c|c|c|c|c|c|c|c|}
\hline \multirow{2}{*}{ Serovares } & \multirow{2}{*}{ № de cepas } & \multicolumn{9}{|c|}{ Antimicrobianos } \\
\hline & & amp & amo & enr & cip & flf & neo & sul & sut & tet \\
\hline Schwarzengrund & 15 & 1 & 5 & 2 & 0 & 0 & 0 & 15 & 1 & 1 \\
\hline Enteritidis & 8 & 0 & 0 & 0 & 0 & 0 & 0 & 6 & 0 & 0 \\
\hline Cerro & 7 & 0 & 0 & 0 & 0 & 0 & 0 & 5 & 0 & 0 \\
\hline Rissen & 4 & 0 & 1 & 1 & 0 & 0 & 0 & 4 & 1 & 1 \\
\hline Johannesburg & 4 & 1 & 1 & 0 & 0 & 0 & 0 & 4 & 3 & 3 \\
\hline Typhimurium & 3 & 0 & 0 & 0 & 0 & 0 & 0 & 3 & 0 & 0 \\
\hline Havana & 3 & 0 & 0 & 0 & 0 & 0 & 0 & 0 & 0 & 0 \\
\hline Mbandaka & 3 & 0 & 0 & 0 & 0 & 0 & 0 & 1 & 1 & 1 \\
\hline Alachua & 2 & 0 & 1 & 0 & 0 & 0 & 0 & 0 & 0 & 0 \\
\hline Hadar & 2 & 0 & 2 & 0 & 0 & 0 & 0 & 0 & 0 & 0 \\
\hline Muenster & 1 & 0 & 0 & 0 & 0 & 0 & 0 & 0 & 0 & 0 \\
\hline Worthington & 1 & 1 & 0 & 0 & 0 & 0 & 0 & 1 & 1 & 1 \\
\hline Total & 53 & 3 & 10 & 3 & 0 & 0 & 0 & 39 & 7 & 7 \\
\hline$\%$ & 100 & 5,7 & 18,9 & 5,7 & 0 & 0 & 0 & 73,6 & 13,2 & 13,2 \\
\hline
\end{tabular}

neo: neomicina; sul: sulfonamidas; tet: tetraciclina; sut: trimetoprim-sulfametoxasol; amo: amoxacilina; amp: ampicilina; cip: ciprofloxacina; enr: enrofloxacina; flf: florfenicol

enterica serovar'Typhimurium, apresentaram alta frequência de resistência às sulfonamidas, 75\% (6/8) e 100\% (3/3), respectivamente (Tabela 3). REzENDE et al. (2005; 2008), ao investigarem a suscetibilidade de Salmonella sp. isoladas de carcaças e vísceras comestíveis, verificaram que $76,5 \%$ foram resistentes à tetraciclina, e 44,1\%, à ampicilina. Ressaltam-se que os estudos foram desenvolvidos na mesma região, em períodos diferentes, evidenciando aumento de cepas de Salmonella sp. resistentes à tetraciclina e ligeira diminuiçãao na frequência de bactérias resistentes à ampicilina.

Ao analisarem o perfil de resistência de 29 cepas de Salmonella sp. oriundas de material de abatedouros, CoRTEZ et al. (2006) encontraram dados diferentes aos obtidos neste estudo. Estes autores observaram $86,2 \%$ de resistência à ampicilina, $72,4 \%$ à tetraciclina e $55,2 \%$ à amoxacilina. Independentemente das frequências descritas, tais pesquisas atentam para elevados percentuais de resistência de Salmonella sp. à ação de antibióticos usados amplamente em medicina humana, podendo causar sérios problemas em saúde pública e no tratamento de animais doentes.

Podem-se observar, na Tabela 4, nove perfis de resistência, sendo que $62,4 \%$ (33/53) das cepas apresentaram padróes de resistência simples, e 20,7\% (11/53) foram multirresistentes a pelo menos dois antimicrobianos testados.

Entre as causas mais comuns para que uma bactéria se torne resistente, podem-se apontar subdosagem, posologia inadequada e indicação incorreta dos antimicrobianos, além do uso por muitas décadas em medicina veterinária e medicina humana. Além desses aspectos, o principal fator
Tabela 4. Perfis de resistência aos antimicrobianos dos isolados de Salmonella sp. de diferentes fontes de isolamento.

\begin{tabular}{ccc}
\hline Antimicrobianos & Número de cepas & $\%$ \\
\hline Amo & $4 / 53$ & 7,5 \\
\hline Sul & $29 / 53$ & 54,7 \\
\hline Resistência simples (total) & $33 / 53$ & 62,4 \\
\hline Amo, Sul & 3 & 5,7 \\
\hline Amo, Enr & 1 & 1,9 \\
\hline Sul, Sut, Tet & 3 & 5,6 \\
\hline Amp, Sul, Sut, Tet & 1 & 1,9 \\
\hline Amo, Enr, Sul, Sut, Tet & 1 & 1,9 \\
\hline Amp, Amo, Sul, Sut, Tet & 1 & 1,9 \\
\hline Amp, Amo, Enr, Sul, Sut, Tet & 1 & 1,9 \\
\hline Resistência múltipla (total) & $11 / 53$ & 20,7 \\
\hline
\end{tabular}

neo: neomicina; sul: sulfonamidas; tet: tetraciclina; sut: trimetoprimsulfametoxasol; amo: amoxacilina; amp: ampicilina; cip: ciprofloxacina; enr: enrofloxacina: flf: florfenicol

relacionado à tal condição no presente estudo seria o contato dos animais com ambientes que albergavam populações bacterianas resistentes. Esse resultado é importante, pois, como destacado por BAUER-GARLAND et al. (2006), bactérias que apresentam múltipla resistência podem se disseminar mais rapidamente de um animal a outro e apresentar menor resposta ao tratamento com antimicrobianos quando infectam outros indivíduos. 
Os resultados obtidos impactam e revelam que cepas isoladas de plantéis de aves destinadas ao consumo podem constituir risco à saúde humana, assim como os prováveis protocolos de tratamento eleitos e recomendados pelos órgãos de saúde, no caso de ser necessária a intervenção medicamentosa. Esses resultados sugerem a necessidade de medidas de avaliação de risco no uso de antimicrobianos em criaçôes de animais.

\section{CONCLUSÕES}

Salmonella encontra-se amplamente distribuída no fluxo de produção de frango de corte, sendo que a via vertical permanece como fonte de introdução do patógeno à cadeia de produção; cama e insetos podem perpetuar e veicular o agente e a existência de cepas resistentes aos antimicrobianos, e a resistência múltipla constitui ameaça à saúde pública.

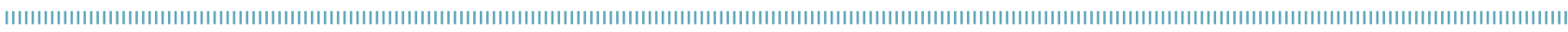

\section{REFERÊNCIAS}

ANDRADE, M.A.; MESQUITA, A.J.; STRINGHINI, J.H.; PEDROSO, A.A.; LEANDRO, N.S.M.; CAFÉ, M.B.; MATTOS, M.S. Infecção experimental de embriões de frango de corte com Salmonella enterica sorovar Enteritidis fago tipo 4. Arquivo Brasileiro de Medicina Veterinária e Zootecnia, v.60, n.5, p.1110-1117, 2008.

BACK, A. Por que os programas de controle para Salmonela em aves falham? Aveworld, v.9, n.54, 2011 . Disponível em: http:// www.aveworld.com.br/artigos/post. Acesso em 27 mar. 2012.

BAUER-GARLAND, J.; FRYE, J.G.; GRAY, J.T.; BERRANG, M.E.; HARRISON, M.A.; FEDORKA-CRAY, P.J. Transmission of Salmonella enterica serotype Typhimurium in poultry with and without antimicrobial selective pressure. Journal of Applied Microbiology, v.101, p.1301-1308, 2006.

BONI, H.F.K. Ocorrência de Salmonella spp. na cadeia avícola da região central de Mata Grosso do Sul. 2007. 42f. Dissertação (Mestrado) - Faculdade de Medicina Veterinária e Zootecnia, Universidade Federal de Mato Grosso do Sul, Campo Grande, 2007.

BORSOI, A.; MORAES, H.S.; SALLE, C.T.P.; BETTIOL, G.E.; LEAL, D.M.; NASCIMENTO, V.P. Sorovares de Salmonella isoladas de carcaças de frangos resfriadas e swab de arrasto. Revista Brasileira de Ciência Avícola, v.8, p.229, 2006.

BRASIL. Ministério da Agricultura e do Abastecimento. Secretaria Nacional da Defesa Agropecuária. Departamento Nacional de Defesa Animal. Coordenação Geral de Laboratório Animal. Métodos de Análises Microbiológicas para Alimentos, Brasília: MAPA, 2003, 226p.

CHERNAKI-LEFFER, A.M.; BIESDORF, S.M.; ALMEIDA, L.M.; LEFFER, E.V.B.; VIGNE, F. Isolamento de enterobactérias em Alphitobiusdiaperinus e na cama de aviários no oeste do Estado do Paraná, Brasil. Revista Brasileira de Ciência Avícola, v.4, n.3, p.243-247, 2002.

CORTEZ, A.L.L.; CARVALHO, A.C.F.B.; IKUNO, A.A.; BURGER, K.P.; VIDAL MARTINS, A.C.M. Resistência antimicrobiana de cepas de Salmonella spp. isoladas de abatedouros de aves. Arquivos do Instituto Biológico. Descalvado, São Paulo, v.73, p.157-163, 2006.

COX, J.M.; PAVIC, A. Advances in enteropathogen control in poultry production. Journal of Applied Microbiology, v. 108, n.3 p.745-755, 2010.
FOOD AND AGRICULTURE ORGANIZATION (FAO/ORG). FoOd safety risk profile for Salmonella species in broiler (young) chickens. CCFH working group on guidelines for control of Campylobacter and Salmonella spp. 2007.

GEORGIA POULTRY LABORATORY. Monitoring and detection of Salmonella in poultry and poultry environments. Oakwood: Georgia Poultry Laboratory, 1997. 293p. [Worshop]

HALD, B. Typhaeastercorea (Coleoptera: Mycetophagidae) a carrier of Salmonella enterica serovar Infantis in a Danish broiler house. Veterinary Entomology, Washington, v.91, n.3, p.660-664, 1998.

HAZELEGER, W.C.; BOLDER, N.M.; BEUMER, R.R.; JACOBSREITSMA, W.F. Darkling beetles (Alphitobiusdiaperinus) and their larvae as potential vectors for the transfer of Campylobacter jejuni and Salmonella enterica serovar Paratyphi B variant java between successive broiler flocks. Applied and Environmental Microbiology, v.74, n.22, p.6887-6891, 2008.

HINTON, A.Jr.; BUHR, R.J.; INGRAN, K.D. Physical, chemical, and microbiological changes in the crop of broiler chickens subjected to incremental feed withdrawal. Poultry Science, v.79, p.212218, 2000.

LEFFER, A.M.; KUTTEL, J.; MARTINS, L.M.; PEDROSO, A.C.; ASTOLFI-FERREIRA, C.S.; FERREIRA, F.; FERREIRA, A.J.P. Vectorial competence of larvae and adults of Alphitobiusdiaperinus in the transmission of Salmonella Enteritidis in poultry. Vector-borne and Zoonotic diseases, v.10, n.5, p.481-487, 2010.

MITCHELL, B.W.; BUHR, R.J.; BERRANG, M.E.; BAILEY, J.S.; COX, N.A. Reducing airborne pathogens, dust and Salmonella transmission in experimental hatching cabinets using an electrostatic space charge system. Poultry Science, v.81, p.49-55, 2002.

NATIONAL COMMITTEE FOR CLINICAL LABORATORY STANDARDS. Bacterial from animal, 2002, $81 \mathrm{p}$.

NEWELL, D.G.; KOOPMANS, M.; VERHOEF, L.; DUIZER, E.; AIDARAKANE, A.; SPRONG, H.; GIESSEN, J. V. D.; KRUSE, H. Food-borne diseases-the challenges of 20 years ago still persist while new ones continue to emerge. International Journal of Food Microbiology, v.139, p.3-15, 2010. 
ORGANIZAÇÃO MUNDIAL DA SAÚDE ANIMAL (OIE). Bioseguridad y resistencia a los antimicrobianos. 2012. Disponível em: http:// www.oie.int/es/para-los-periodistas/comunicados-de-prensa. Acesso em: 11 jan. 2012.

REZENDE, C.S.M.; ANDRADE, M.A.; MESQUITA, A.J.; COELHO, K.O.; MINAFRA, C.S.; ARRUDA, M.LT.; LAGE, M.E. Salmonella sp. em corações e fígados normais e condenados de frangos de corte abatidos no estado de Goiás e identificação da suscetibilidade a antimicrobianos. Revista do Instituto Adolfo Lutz, v.67, n.2, p.142-147, 2008.

REZENDE, C.S.M.; MESQUITA, A.J.; ANDRADE, M.A.; LINHARES, G.F.C.; MESQUITA, A.Q.; MINAFRA, C.S. Sorovares de Salmonella isolados de carcaças de frangos de corte abatidos no Estado de Goiás, Brasil, e perfil de resistência a antimicrobiano. Revista Portuguesa de Ciência Veterinária, v.100, n.555-556, p.199-203, 2005.

ROCHA, P. T.; MESQUITA, A. J.; ANDRADE, M. A.; LOULY, P. R.; NASCIMENTO, M. N. Salmonella spp. em forros de caixa de transporte e órgãos de pintos de um dia. Arquivo Brasileiro de Medicina Veterinária e Zootecnia, v.55, n.6, p.676-676, 2003.

ROCHE, A.J.; COX, N.A.; RICHARDSON, L.J.; BUHR, R.J.; CASON, J.A.; FAIRCHILD, B.D.; HINKLE, N.C. Transmission of Salmonella to broilers by contaminated larval and adult lesser meal worms, Alphitobiu sdiaperinus (Coleoptera: Tenebrionidae). Poultry Science, v.88, p.44-48, 2009.

RODRIGUES, D.P. Ecologia e prevalência de Salmonella spp. em aves e materiais avícolas. Facta, Campinas, v.2, p.223-228, 2005. In: CONFERÊNCIA APINCO 2005 DE CIÊNCIAS E TECNOLOGIAS AVÍCOLAS, 2005, Campinas.
SEGABINAZI, S.D.; FLORES, M. L.; BARCELOS, A. S.; JACOBSEN, G.; ELTZ, R. D. Bactérias da família Enterobacteriaceae em Alphitobiusdiaperinusoriundos de granjas avícolas do estado do Rio Grande do Sul e Santa Catarina, Brasil. Acta Scientiae Veterinariae, v.33, p.51-55, 2005.

SCHLUNDT, J.; TOYOFUKU, H.; JANSEN, J.; HERBST, S. A. Emerging food-borne zoonoses. Revue scientifique et technique, v.23, n.2, p.513-533, 2004

SILVA, A.B.A. Influência do jejum alimentar, probióticos e antibiótico na população de enterobactérias, bactérias ácido lácticas, Bacillus e Salmonellasp. em cecos e papos de frangos de corte. 2006. 71 f. Dissertação (Mestrado em Ciência) - Escola Superior de Agricultura "Luiz de Queiroz", Universidade de São Paulo, Piracicaba, 2006.

SILVA, E.N. Medidas gerais de controle de salmonelas em frangos. Facta, Campinas, p.229-237, 2005. In: CONFERÊNCIA APINCO 2005 DE CIÊNCIA E TECNOLOGIA AVÍCOLAS, 2005, Campinas.

VIEIRA, V.R.; NASCIMENTO, V.P.; BORSOI, A.; SANTOS, L.R. Número mais provável (NMP) de Salmonella sp. em cecos de frangos de corte e correlação e correlação com a população linfocitária bursal. Acta Scientiae Veterinariae, v.35, n. 1, p.4953, 2007.

YANG, B.; QU, D.; ZHANG, X.; SHEN, J.; CUI, S.; SHI, Y.; XI, M.; SHENG, M.; ZHI, S.; MENG, J. Prevalence and characterization of Salmonella serovars in retail meats of marketplace in Shaanxi, China. International Journal of Food Microbiology, v.141, n.1-2, p.63-72, 2010. 